\title{
Step-by-Step Real Time Monitoring of a Catalytic Amination Reaction
}

Gilian T. Thomas, Eric Janusson, Harmen S. Zijlstra, J Scott Mclndoe

Submitted date: 28/06/2019 Posted date: 01/07/2019

Licence: CC BY-NC-ND 4.0

Citation information: Thomas, Gilian T.; Janusson, Eric; Zijlstra, Harmen S.; Mclndoe, J Scott (2019):

Step-by-Step Real Time Monitoring of a Catalytic Amination Reaction. ChemRxiv. Preprint.

The multiple reaction monitoring mode of a triple quadrupole mass spectrometer is used to examine the Buchwald-Hartwig amination reaction at $0.1 \%$ catalyst loading in real-time using sequential addition of reagents to probe the individual steps in the cycle. This is a powerful new method for probing reactions under realistic conditions.

File list (3)

manuscript.docx (1.07 MiB)

SI.docx (57.83 KiB)

manuscript.pdf (486.33 KiB) view on ChemRxiv • download file view on ChemRxiv • download file

view on ChemRxiv • download file 


\title{
Step-by-step real time monitoring of a catalytic amination reaction
}

\author{
Gilian T. Thomas, Eric Janusson, Harmen S. Zijlstra, J. Scott McIndoe* \\ Department of Chemistry, University of Victoria, PO Box 1700 STN CSC, Victoria, BC V8W \\ 2Y2, Canada. \\ Fax: +1 (250) 721-7147; Tel: +1 (250) 721-7181; E-mail: mcindoe@uvic.ca
}

\begin{abstract}
The multiple reaction monitoring mode of a triple quadrupole mass spectrometer is used to examine the Buchwald-Hartwig amination reaction at $0.1 \%$ catalyst loading in real-time using sequential addition of reagents to probe the individual steps in the cycle. This is a powerful new method for probing reactions under realistic conditions.
\end{abstract}

\section{Graphical abstract}

\section{Keywords}

Buchwald-Hartwig, amination, cross-coupling, palladium, mass spectrometry, real-time analysis, multiple reaction monitoring 


\section{Introduction}

One of the most common ways to form $\mathrm{C}-\mathrm{N}$ bonds is the Buchwald-Hartwig amination. ${ }^{1-4}$ This versatile palladium-catalyzed cross-coupling between amines and aryl or vinyl halides is widely used and new applications are reported frequently. ${ }^{5-14}$ The reaction mechanism is thought to involve oxidative addition of the aryl halide to $\operatorname{Pd}(0)$, coordination of the aniline, deprotonation by base, and reductive elimination of the new $\mathrm{C}-\mathrm{N}$ bond regenerating the $\operatorname{Pd}(0)$ catalyst. ${ }^{15-17}$ Improved understanding of the reaction and observation of the intermediates during this reaction will aid the further development of catalysts and ligands, as well as provide a thorough understanding of substrate effects, allowing optimization of every reaction component.

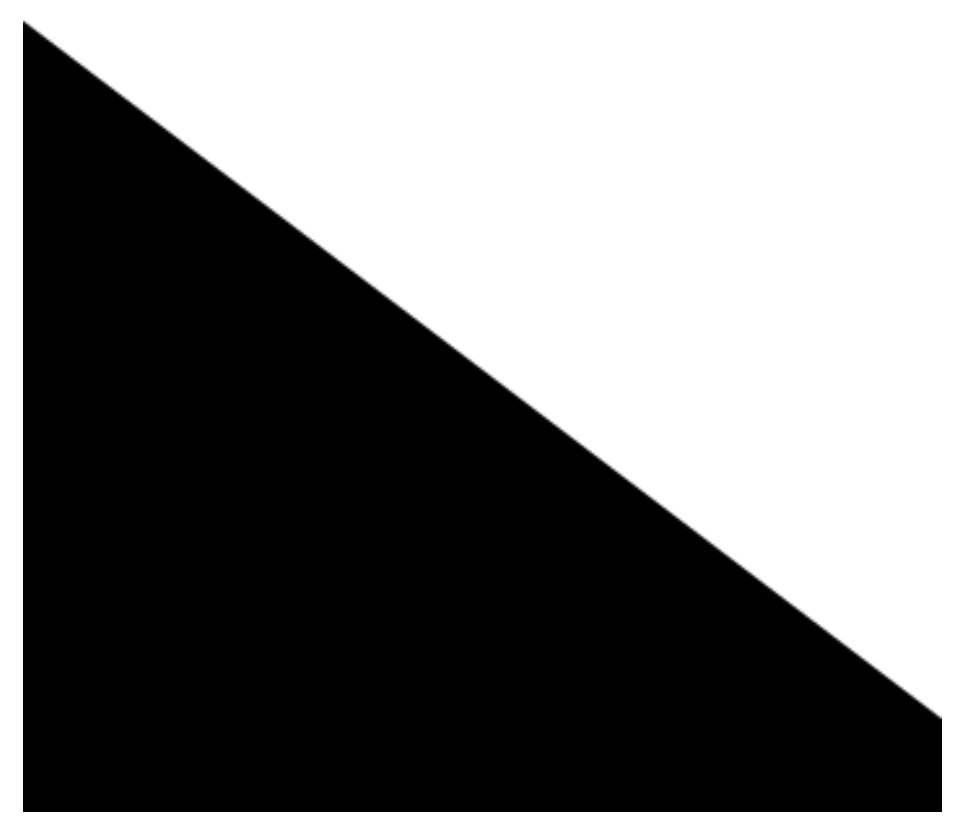

Scheme 1. Generally accepted mechanism for catalytic amination as mediated by palladium(0) complexes. $^{17-24}$

The reaction has been studied by a variety of spectroscopic methods, and the catalytic cycle is fairly well established under certain conditions (Figure 1), however is not entirely understood due to the complexity of the reaction. Hartwig and coworkers determined the reaction order in aryl halide using ${ }^{31} \mathrm{P}$ and ${ }^{1} \mathrm{H}$ NMR with three different palladium catalysts, and found that the rate 
limiting step is the reductive elimination. ${ }^{25}$ Examination of various $p$-aryl bromides revealed that the rate was faster as the electron density at the aryl ring decreased. The reaction was shown to be zero order in added phosphine, zero order in aryl halide, and first order in tin amide; the order in palladium complex differed depending on the catalyst. The same team studied the reductive elimination step of the reaction using ${ }^{31} \mathrm{P}$ and ${ }^{1} \mathrm{H} N M R$ and UV/Vis to perform kinetic analysis on seven isolated palladium amido complexes. ${ }^{17}$ The reductive elimination was accelerated by electron withdrawing groups on the aryl group (acting as electrophile) and by electron-donating groups on the amido ligand (acting as nucleophile). Buchwald and coworkers studied palladium-catalyzed formation of unsymmetrical ureas via cross-coupling of aryl chlorides and triflates, and conducted competition experiments between the aryl chloride and aryl bromide and determined that transmetalation is the rate limiting step. ${ }^{26}$ They also studied the reaction between aniline and 4-iodotoluene in toluene with various ligands and found that BrettPhos had the highest GC yield. ${ }^{27}$ For morpholine and 4-iodoanisole RuPhos gave the highest GC yield. Solvent effects were studied using aniline and 4-haloanisole, and it was found that dioxane and DME accelerated the reaction for 4-bromoanisole but did not have a significant effect on 4-iodoanisole. The reaction was inhibited by the Nal byproduct when using NaOt-Bu as base, so $\mathrm{Cs}_{2} \mathrm{CO}_{3}$ was used instead.

Electrospray ionization mass spectrometry (ESI-MS) has previously been shown to be a valuable tool in studying catalytic reactions. ${ }^{28,29}$ The high sensitivity of the instrument facilitates detection of transient catalytic intermediates which are difficult to detect using other techniques. Additionally, pressurized sample injection (PSI) allows for simple continuous real-time monitoring of air or moisture sensitive reactions. ${ }^{30}$

We have recently investigated the activation of $\mathrm{Pd}_{2}(\mathrm{dba})_{3}$, a popular catalyst precursor for the Buchwald-Hartwig amination. ${ }^{31}$ We now extend this to monitoring the full Buchwald-Hartwig amination cycle using the hydrophilic sulfonated Buchwald-type ligand $\mathrm{Na}^{+}[\mathrm{sSPhos}]^{-32}$ This ligand is advantageous for mechanistic studies involving ESI-MS, as it carries a charge that it can confer to any complex to which it is bound, enabling straightforward detection during analysis. ${ }^{33,34}$ The Buchwald-Hartwig reaction is a challenging target for analysis under normal synthetic conditions, thanks to its high efficiency allowing catalyst loadings as low as $0.1 \%{ }^{35}$ 


\section{Results and discussion}

Analysis of a catalytic reaction by PSI-ESI-MS requires all species of interest to be charged, and this can be achieved by using an inherently charged catalyst, by employing a charged substrate, or by modifying the ligand environment to include a charged ligand. ${ }^{29}$ The last of these approaches was used here, thanks to the commercial availability of the ideal candidate: a sulfonated SPhos ligand, sSPhos (from now on represented as L). A triple quadrupole mass spectrometer in multiple reaction monitoring (MRM) mode was used in order to detect the low concentrations of catalytically relevant species present in a typical amination reaction. MRM mode applies a double filter to the analysis: the first quadrupole is fixed on a desired $\mathrm{m} / \mathrm{z}$ value (in the case of the broad Pd-containing isotope patterns analyzed herein, the most abundant isotopomer), it is fragmented using collision-induced dissociation (CID) in the collision cell (not always a quadrupole, despite the name - in the case of this instrument, the collision cell is a hexapole), while the third quadrupole is fixed on a characteristic product ion. This technique excludes noise and isobaric species (ions appearing at the same $\mathrm{m} / \mathrm{z}$ ), and the signal-to-noise ratio of the analysis is enhanced because the instrument does not spend time scanning the parts of the spectrum of no interest. MRM can be configured such that many different ions can be interrogated on a fast duty cycle, so the effective scan time (time between individual measurements) is of the order of seconds - very fast relative to most spectroscopic methods. In this context "multiple reactions" refers to the unimolecular decomposition reactions (fragmentations) that happen to the selected ions in the collision cell. MRM has been used extensively to characterize complex biological processes, such as enzymatic catalysis, protein and proteome analysis, and biomarker detection. ${ }^{36-39}$ However, very few applications in organometallic reaction chemistry and homogeneous catalysis have been reported. ${ }^{40}$

In a simple amination reaction, we were able to monitor the formation of key species present in the proposed cycle (Figure 1). By adding reagents sequentially, high quality mass spectra of each component could be collected and their isotope patterns and exact $\mathrm{m} / \mathrm{z}$ values compared against calculated values (these collected on a high resolution hybrid quadrupole-TOF instrument).

Step 1: Catalyst activation 
The first step of the cycle is transforming the catalyst precursor, $\operatorname{Pd}_{2}(\mathrm{dba})_{3}$, into the catalyst resting state. Our previous study of the reaction of $\mathrm{Pd}_{2}(\mathrm{dba})_{3}$ with sulfonated phosphines, $\left[\mathrm{PPh}_{2}\left(\mathrm{C}_{6} \mathrm{H}_{4} \mathrm{SO}_{3}\right]^{-}\right.$and $\mathrm{L}$, using ESI-MS and UV/Vis spectroscopy, ${ }^{31}$ revealed that the only product of catalyst activation in the $L$ case to be $[\mathrm{Pd}(\mathrm{L})(\mathrm{dba})]^{-}$. This result was replicated here, with a fast and first-order reaction observed with a $t_{1 / 2}=0.3$ minutes (Figure 1, 1-3 minutes).

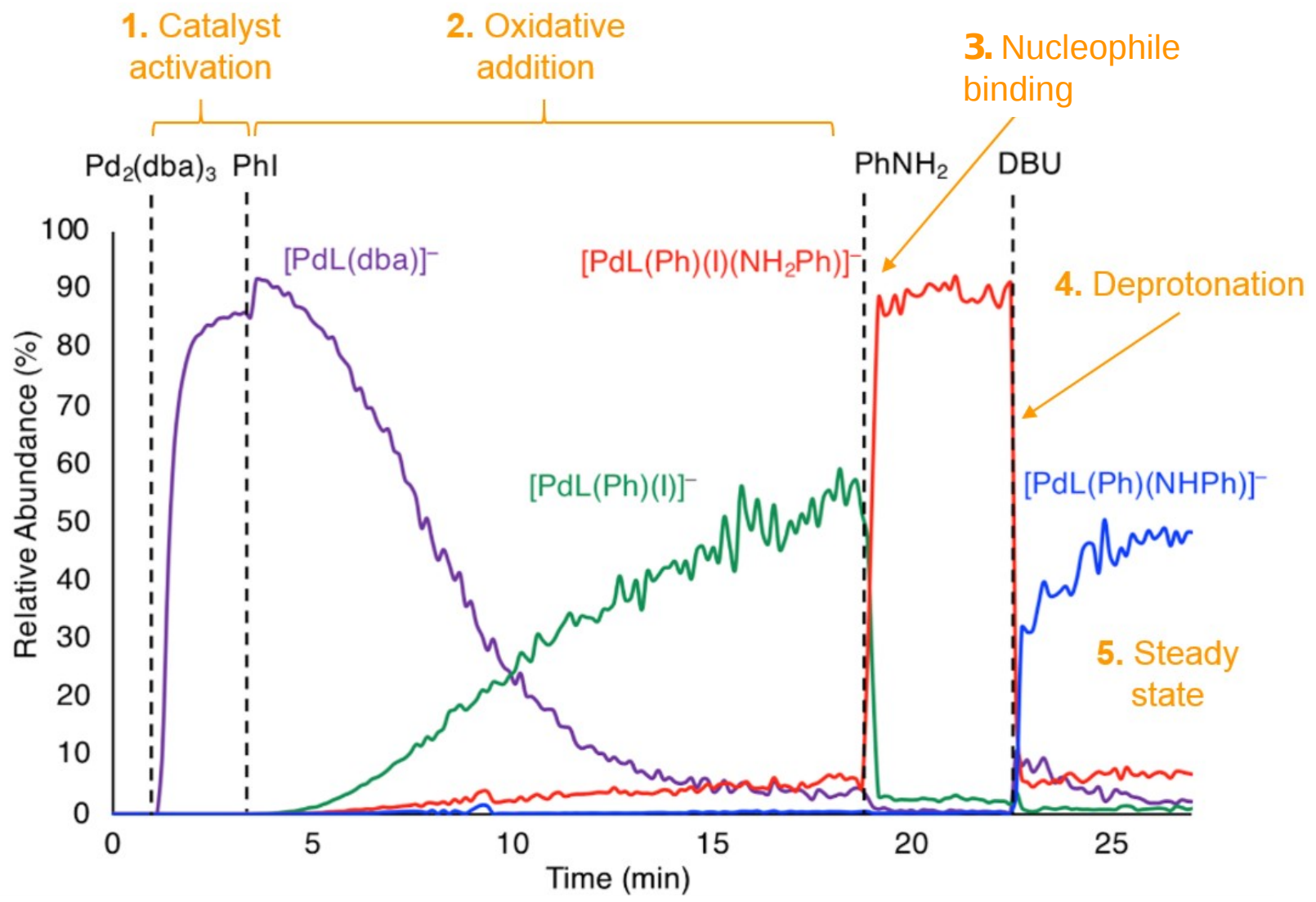

Figure 1. Sequential addition of reaction components to probe rates of reaction.

Step 2: Oxidative addition

Once catalyst activation was complete, an excess of iodobenzene was added, which resulted in the disappearance of $[\mathrm{Pd}(\mathrm{L})(\mathrm{dba})]^{-}$to be replaced predominantly with $[\mathrm{Pd}(\mathrm{L})(\mathrm{Ph})(\mathrm{I})]^{-}$(Figure 1, 3-19 minutes). Small amounts of $\left[\mathrm{Pd}(\mathrm{L})(\mathrm{Ph})(\mathrm{I})\left(\mathrm{PhNH}_{2}\right)\right]^{-}$were also observed, due to the trace levels of aniline present in commercial Phl. ${ }^{41}$ The differences in rate of $[\mathrm{Pd}(\mathrm{L})(\mathrm{dba})]^{-}$consumed vs. $[\mathrm{Pd}(\mathrm{L})(\mathrm{Ph})(\mathrm{I})]^{-}$appearing indicated that some other unobserved intermediate was involved. The most obvious candidate for this was the zwitterionic $\operatorname{Pd}(L)(P h)$, as cationic $\left[L_{2} P d(\operatorname{Ar})\right]^{+}$ 
species are a feature of $\mathrm{L}_{2} \mathrm{Pd}(\mathrm{Ar})(\mathrm{X})$ complexes in polar solvents. ${ }^{42}$ Accordingly, we performed the experiment with $\operatorname{SPhos}^{43}$ instead of $L$ (i.e. the same ligand, but unsulfonated), and saw the expected production of $[\mathrm{Pd}(\mathrm{SPhos})(\mathrm{Ph})]^{+}$in the positive ion mode (Figure S2). The oxidative addition was not particularly rapid, presumably due to the necessity of dba decoordination prior to the reaction taking place. ${ }^{44}$ The disappearance of $[\mathrm{Pd}(\mathrm{L})(\mathrm{dba})]^{-}$produced a linear plot of the natural log of the abundance of $[\mathrm{Pd}(\mathrm{L})(\mathrm{dba})]^{-}$vs time for the last 10 minutes of the 15 minutes the reaction took to reach equilibrium (Figure S1), and during this period $t_{1 / 2}=1.3$ minutes.

\section{Step 3 - Addition of aniline}

Addition of aniline to the reaction mixture caused immediate disappearance of the signal for $[\mathrm{Pd}(\mathrm{L})(\mathrm{Ph})(\mathrm{I})]^{-}$, to be replaced by $\left[\mathrm{Pd}(\mathrm{L})(\mathrm{Ph})(\mathrm{I})\left(\mathrm{PhNH}_{2}\right)\right]^{-}$(Figure 1, 19 minutes). This reaction was faster than the time resolution of the PSI-ESI-MS experiment, which takes some 20 seconds for the solution to move from the reaction flask to the mass spectrometer. ${ }^{45}$ As such, all we can say is that $t_{1 / 2}<20 \mathrm{~s}$. In the positive ion mode ( $L=$ SPhos), we did not see the aniline coordinate to the cationic $[\mathrm{PdL}(\mathrm{Ph})]^{+}$, but we did see a sharp increase in the amount of $[\mathrm{PdL}(\mathrm{Ph})]^{+}$, suggesting that the aniline does not strongly bind to the cation but does facilitate the displacement of the iodide ligand.

Step 4 - Addition of base

Deprotonation of the bound aniline was just as fast as association of the aniline to the palladium in the previous step, i.e. a $t_{1 / 2}$ of $<20$ seconds (Figure 1, 22.5 minutes). The product was $[\mathrm{PdL}(\mathrm{Ph})(\mathrm{NHPh})]^{-}$, i.e. the deprotonation was concomitant with iodide loss. Note however that the immediate product of deprotonation of $\left[\mathrm{PdL}(\mathrm{Ph})(\mathrm{I})\left(\mathrm{NH}_{2} \mathrm{Ph}\right]^{-}\right.$would be $[\mathrm{PdL}(\mathrm{Ph})(\mathrm{I})(\mathrm{NHPh})]^{2-}$, and because dianions have a limited existence in the gas phase, we would not expect to observe it as iodide loss would be facile.

Selection of DBU as the base in this reaction prevents formation of Nal species which have been shown to have an inhibitory effect on the reaction. ${ }^{27,46}$ Additionally, performing the reaction in a stepwise fashion rather than 'one-pot', prevents observation of base-bound intermediates previously reported, whereby the resting state was determined to be a DBU-bound species after 
the oxidative addition. ${ }^{47}$ Thus the stepwise catalytic cycle has an alternate steady state, discernible in real-time by mass spectrometry.

\section{Step 5 - Reductive elimination}

After addition of base, the amount of $[\mathrm{PdL}(\mathrm{Ph})(\mathrm{NHPh})]^{-}$did not change significantly in the following 30 minutes or so (Figure 2, first few minutes of this process only shown from 23 minutes). A small amount of $[\mathrm{Pd}(\mathrm{L})(\mathrm{dba})]^{-}$was regenerated after addition of base, suggesting some turnover of the reaction was occurring, though $[\mathrm{PdL}(\mathrm{Ph})(\mathrm{NHPh})]^{-}$was the dominant catalytically-relevant species and is therefore assigned as the catalyst resting state. Because reductive elimination is a unimolecular decomposition, the transformation could be simulated in the gas phase using collision-induced dissociation (CID). ${ }^{33}$ This reaction has the benefit of being able to be performed in isolation from any other solution components, and is therefore uncomplicated by further reactivity. Collisions with argon gas resulted exclusively in reductive elimination of $\mathrm{Ph}_{2} \mathrm{NH}$, with no ligand dissociation observed at all (Figure 2).

Using reaction calorimetry, this step was previously established to be rate-limiting in triarylamine formation via C-N coupling due to the low nucleophilicity of diarylamines. ${ }^{48}$ However, it was found that the catalytic cycle is in a steady state at $[\mathrm{Pd}(\mathrm{L})(\mathrm{Ph})(\mathrm{NHPh})]^{-}$in the formation of diarylamine due to the stepwise addition, as mentioned in the previous section.

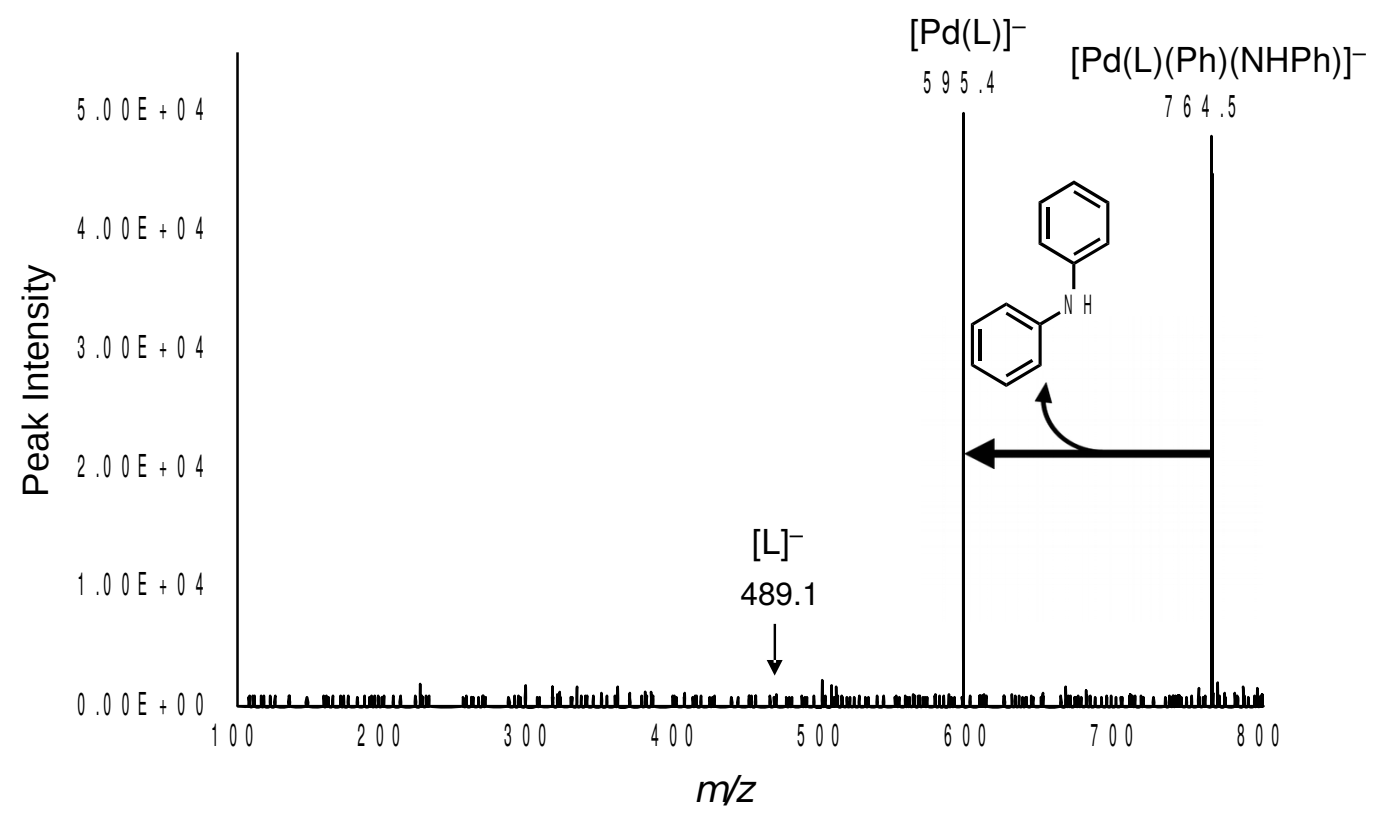


Figure 2. Product ion mass spectrum of $[\mathrm{Pd}(\mathrm{L})(\mathrm{Ph})(\mathrm{NHPh})]^{-}$. Energetic gas-phase collisions between $[\mathrm{Pd}(\mathrm{L})(\mathrm{Ph})(\mathrm{NHPh})]^{-}$and argon atoms results in the exclusive formation of $[\mathrm{Pd}(\mathrm{L})]^{-}$via loss of reductively eliminated $\mathrm{HNPh}_{2}$.

Real-time analysis of the Buchwald-Hartwig amination reaction using a triple quadrupole ESI mass spectrometer in multiple reaction monitoring mode revealed rate information on each individual step of the cycle. These data can be summarized in a single set of traces (Figure 1), and as a catalytic cycle (Scheme 2) whereby the weight of the arrows indicates the relative magnitude of the (pseudo) first order rate constant of each elementary step in the cycle.

Scheme 2. Catalytic cycle with arrows weighted by relative rate constants of each reaction. ${ }^{49}$

\section{Conclusions}

Online reaction monitoring using pressurized sample infusion electrospray ionization mass spectrometry (PSI-ESI-MS) is a viable and powerful method of catalytic mechanism analysis. This is the first reported instance of using multiple reaction monitoring (MRM) scans to observe and quantify catalytically relevant species. Relative rates of reaction were elucidated, and it was 
found that the resting state is the $[\mathrm{Pd}(\mathrm{L})(\mathrm{Ph})(\mathrm{NHPh})]^{-}$species in the formation of diphenylamine via coupling iodobenzene and aniline. 


\section{References}

1 D. S. Surry and S. L. Buchwald, Chem. Sci., 2011, 2, 27-50.

2 H. Christensen, S. Kiil, K. Dam-Johansen, O. Nielsen and M. B. Sommer, Org. Process Res. Dev. , 2006, 10, 762-769.

3 I. J. S. Fairlamb, A. R. Kapdi, A. F. Lee, G. P. McGlacken, F. Weissburger, A. H. M. de Vries and L. Schmieder-van de Vondervoort, Chem. Eur. J., 2006, 12, 8750-8761.

4 B. T. Ingoglia, C. C. Wagen and S. L. Buchwald, Tetrahedron, 2019, In Press.

5 P. Ruiz-Castillo and S. L. Buchwald, Chem. Rev., 2016, 116, 12564-12649.

6 A. Gangjee, O. A. Namjoshi, S. Raghavan, S. F. Queener, R. L. Kisliuk and V. Cody, J. Med. Chem., 2013, 56, 4422-41.

7 L. Wang, H. Neumann, A. Spannenberg and M. Beller, Chem. Eur. J., 2018, 24, 21642172.

8 A. S. Guram, Org. Process Res. Dev., 2016, 20, 1754-1764.

9 C. Valente, M. Pompeo, M. Sayah and M. G. Organ, Org. Process Res. Dev., 2014, 18, 180-190.

10 C. Wiethan, W. C. Rosa, H. G. Bonacorso and M. Stradiotto, Org. Biomol. Chem., 2016, 14, 2352-2359.

11 M. A. MacLean, E. Diez-Cecilia, C. B. Lavery, M. A. Reed, Y. Wang, D. F. Weaver and M. Stradiotto, Bioorg. Med. Chem. Lett., 2016, 26, 100-104.

12 D. Nandi, R. U. Islam, N. Devi, S. Siwal and K. Mallick, New J. Chem., 2018, 42, 812816.

13 C. Lombardi, J. Day, N. Chandrasoma, D. Mitchell, M. J. Rodriguez, J. L. Farmer and M. G. Organ, Organometallics, 2017, 36, 251-254.

14 P. G. Gildner, A. DeAngelis and T. J. Colacot, Org. Lett., 2016, 18, 1442-1445.

15 K. H. Hoi, S. Çalimsiz, R. D. J. Froese, A. C. Hopkinson and M. G. Organ, Chem. Eur. J., 2012, 18, 145-151.

16 Y. Sunesson, E. Limé, S. O. Nilsson Lill, R. E. Meadows and P.-O. Norrby, J. Org. Chem., 2014, 79, 11961-11969.

17 M. S. Driver and J. F. Hartwig, J. Am. Chem. Soc., 1997, 119, 8232-8245.

18 R. A. Widenhoefer and S. L. Buchwald, Organometallics, 1996, 15, 2755-2763.

19 M. S. Driver and J. F. Hartwig, J. Am. Chem. Soc., 1995, 117, 4708-4709.

20 J. F. Hartwig, S. Richards, D. Barañano and P. Frédéric, J. Am. Chem. Soc., 1996, 118, 
3626-3633.

21 A. S. Guram, R. A. Rennels and S. L. Buchwald, Angew. Chemie , 1995, 34, 1348-1350.

22 J. Louie and J. F. Hartwig, Tetrahedron Lett., 1995, 36, 3609-3612.

23 A. S. Guram and S. L. Buchwald, J. Am. Chem. Soc., 1994, 116, 7901-7902.

24 F. Paul, J. Patt and J. F. Hartwig, J. Am. Chem. Soc., 1994, 116, 5969-5970.

25 J. Louie, P. Frédéric and J. F. Hartwig, Organometallics, 1996, 15, 2794-2805.

26 E. V Vinogradova, B. P. Fors and S. L. Buchwald, J. Am. Chem. Soc, 2012, 134, 1113211135.

27 B. P. Fors, N. R. Davis and S. L. Buchwald, J. Am. Chem. Soc., 2009, 131, 5766-5768.

28 K. L. Vikse, Z. Ahmadi and J. S. Mcindoe, Coord. Chem. Rev., 2014, 279, 96-114.

29 L. P. E. Yunker, R. L. Stoddard and J. S. McIndoe, J. Mass Spectrom., 2014, 49, 1-8.

30 K. L. Vikse, M. P. Woods and J. S. Mcindoe, Organometallics, 2010, 29, 6615.

31 E. Janusson, H. S. Zijlstra, P. P. T. Nguyen, L. Macgillivray, J. Martelino and J. S. Mcindoe, Chem. Commun, 2017, 854, 854-856.

32 K. W. Anderson and S. L. Buchwald, Angew. Chemie Int. Ed., 2005, 44, 6173-6177.

33 K. L. Vikse, M. A. Henderson, A. G. Oliver and J. S. McIndoe, Chem. Commun., 2010, 46, 7412.

34 D. M. Chisholm and J. Scott McIndoe, Dalt. Trans., 2008, 3933.

35 S. Urgaonkar and J. G. Verkade, J. Org. Chem., 2004, 69, 9135-9142.

36 B. Domon and R. Aebersold, Science (80-. )., 2006, 312, 212-217.

37 S. A. Carr and L. Anderson, Clin. Chem., 2008, 54, 1749-52.

38 A. J. Norris, J. P. Whitelegge, K. F. Faull and T. Toyokuni, Biochemistry, 2001, 40, 37743779.

39 A. J. Norris, J. P. Whitelegge, K. F. Faull and T. Toyokuni, Anal. Chem., 2001, 73, 60246029.

40 Y. Wang, W.-Y. Lin, K. Liu, R. J. Lin, M. Selke, H. C. Kolb, N. Zhang, X.-Z. Zhao, M. E. Phelps, C. K. F. Shen, K. F. Faull and H.-R. Tseng, Lab Chip, 2009, 9, 2281-2285.

41 Repeated washing with acid was required to reduce aniline contamination to the levels shown. At a catalyst loading of $0.1 \%$, observing aniline binding suggested a contamination level of $\sim 0.1 \%$ (ppm), .

42 L. P. E. Yunker, Z. Ahmadi, J. R. Logan, W. Wu, T. Li, A. Martindale, A. G. Oliver and J. S. McIndoe, Organometallics, 2018, 37, 4297-4308.

43 Timothy E. Barder, Shawn D. Walker, A. Joseph R. Martinelli and S. L. Buchwald, J. Am. Chem. Soc., 2005, 127, 4685-4696. 
44 P. Weber, A. Biafora, A. Doppiu, H.-J. Bongard, H. Kelm and L. J. Gooßen, Org. Process Res. Dev., , DOI:10.1021/acs.oprd.9b00214.

45 K. L. Vikse, Z. Ahmadi, J. Luo, N. Van Der Wal, K. Daze, N. Taylor and J. S. Mcindoe, Int. J. Mass Spectrom., 2012, 323, 8-13.

46 J. M. Dennis, N. A. White, R. Y. Liu and S. L. Buchwald, J. Am. Chem. Soc., 2018, 140, 4721-4725.

47 J. M. Dennis, N. A. White, R. Y. Liu and S. L. Buchwald, ACS Catal., 2019, 9, 3822-3830.

48 P. L. Arrechea and S. L. Buchwald, J. Am. Chem. Soc., 2016, 138, 12486-12493.

49 J. McFarlane, B. Henderson, S. Donnecke and J. S. Mclndoe, ChemRxiv, , DOI:https://doi.org/10.26434/chemrxiv.8206637.v1. 


\title{
Step-by-step real time monitoring of a catalytic amination reaction SUPPORTING INFORMATION
}

\author{
Gilian T. Thomas, Eric Janusson, Harmen S. Zijlstra, J. Scott Mclndoe*
}

Department of Chemistry, University of Victoria, P.O. Box 3065 Victoria, BC V8W3V6, Canada. Fax: +1 (250) 721-7147; Tel: +1 (250) 721-7181; E-mail: mcindoe@uvic.ca

\section{Experimental}

Tris(dibenzylideneacetone)dipalladium $(0) \quad\left(\mathrm{Pd}_{2}(\mathrm{dba})_{3}\right)$, sodium 2'-dicyclohexylphosphino-2,6dimethoxy-1,1'-biphenyl-3-sulfonate hydrate (sSPhos), aniline (99\%), iodobenzene (98\%), 1,8diazabicyclo[5.4.0]undec-7-ene (DBU) (98\%), and HPLC grade methanol were purchased from Sigma-Aldrich and used as is unless specified otherwise. UHP200 Argon and HP300 4.8 Nitrogen were purchased from Airgas (Calgary, Canada) and used without further purification.

\section{Preparation of reagents and solvents}

All reagent stock solutions were prepared under an inert nitrogen atmosphere in a Schlenk flask or in a glovebox. $\mathrm{Pd}_{2}(\mathrm{dba})_{3}$ stock solution was prepared using $0.0045 \mathrm{~g} \mathrm{Pd}_{2}(\mathrm{dba})_{3}$ dissolved in $4.0 \mathrm{~mL}$ tetrahydrofuran (dried/refluxed over $\mathrm{CaH}_{2}$ and distilled under $\mathrm{N}_{2}$ ) (1.2 mM Pd). sSPhos (sodium 2-dicyclohexylphosphino-2',6'-dimethoxybiphenyl-3'-sulfonate) stock was prepared by dissolving $0.0045 \mathrm{~g}$ of the salt in $4.0 \mathrm{~mL}$ HPLC-grade methanol previously dried over $\mathrm{CaH}_{2}(2.1$ $\mathrm{mM})$.

In a typical reaction, $20.0 \mathrm{~mL}$ of HPLC-grade methanol previously dried/refluxed over $\mathrm{CaH}_{2}$ and freshly distilled under $\mathrm{N}_{2}$, was transferred to a custom Schlenk flask fitted with a condenser, ${ }^{1}$ sparged with nitrogen for 15 minutes, and connected to the mass spectrometer via PEEK tubing passed through a rubber septum. Heating was effected with an IKA C-MAG HS 7 stirring hotplate equipped with an ETS-D5 thermocouple and oil bath. The thermocouple was set to heat the oil bath to $80^{\circ} \mathrm{C}$. All reagent stock solutions were prepared under an inert nitrogen atmosphere in a glovebox. An aliquot of sSPhos was injected into the flask, followed by $\mathrm{Pd}_{2}(\mathrm{dba})_{3}$ to initiate the reaction. Iodobenzene was purified by washing 3 times with $10 \% \mathrm{HCl}$, followed by a freeze-pump-thaw. The remaining reagents were freeze-pump-thawed, and added 
stepwise via syringe.

\section{Mass Spectrometry Analysis}

All electrospray ionization mass spectra were recorded using a Waters Acquity Triple Quadrupole Detector equipped with a Z-Spray electrospray ionization source. The capillary voltage was held at $3.0 \mathrm{kV}$, cone voltage at $10.0 \mathrm{~V}$, and extraction cone at $3.0 \mathrm{~V}$. The MS cone voltage was optimized to eliminate in-source fragmentation of the catalyst. The desolvation gas flow rate was $500 \mathrm{~L} / \mathrm{hr}$, cone gas flow rate $100 \mathrm{~L} / \mathrm{hr}$, source temperature $80^{\circ} \mathrm{C}$, desolvation temperature $210^{\circ} \mathrm{C}$. The RF lens was set to an optimal voltage of $0.3 \mathrm{~V}$. For full scan experiments, scan time was set to $10 \mathrm{~s}$, with an inter-scan time of $0.1 \mathrm{~s}$ and a range of $\mathrm{m} / \mathrm{z} 400$ 1000. MRM experiments were performed with a collision energy between 5-35 $\mathrm{V}$ with an argon collision gas flow rate of $0.1 \mathrm{~mL} / \mathrm{hr}$. The full MRM parameter list is below in Table 1.

Table 1: MRM scan specifications for each intermediate.

\begin{tabular}{|l|l|l|l|l|}
\hline Species & Parent $m / z$ & Fragment $m / z$ & Dwell Time (s) & $\begin{array}{l}\text { Collision Energy } \\
(\mathrm{V})\end{array}$ \\
\hline$[\mathrm{sSPhos}]^{-}$ & 489 & 375.4 & 0.2 & 35 \\
\hline$[\mathrm{Pd}(\mathrm{L})(\mathrm{NHPh})(\mathrm{Ph})]^{-}$ & 764 & 595.1 & 1.5 & 5 \\
\hline$[\mathrm{Pd}(\mathrm{L})(\mathrm{Ph})(\mathrm{l})]^{-}$ & 799 & 127 & 1.5 & 20 \\
\hline$[\mathrm{Pd}(\mathrm{L})(\mathrm{dba})]^{-}$ & 829 & 595.3 & 1.5 & 25 \\
\hline$\left[\mathrm{Pd}(\mathrm{L})\left(\mathrm{NH}_{2} \mathrm{Ph}\right)(\mathrm{Ph})(\mathrm{l})\right]^{-}$ & 892 & 799.2 & 1.5 & 7 \\
\hline
\end{tabular}

\section{Calculation of Rate Constants}

$[\mathrm{Pd}(\mathrm{L})(\mathrm{dba})]^{-}$

slope $=-0.3398$, first order therefore $k=0.3 \mathrm{~s}^{-1}$.

$[\mathrm{Pd}(\mathrm{L})(\mathrm{Ph})(\mathrm{I})]^{-}$

slope $=-4.3132$, pseudo-first-order therefore: $k^{\prime}=4.3132(0.0898 \mathrm{M})=/>0.3873 \mathrm{~s}^{-1}$

$\left[\mathrm{Pd}(\mathrm{L})(\mathrm{Ph})(\mathrm{I})\left(\mathrm{NH}_{2} \mathrm{Ph}\right)\right]^{-}$

slope $=-3.768$, pseudo-first-order therefore: $k^{\prime}=3.768(0.1095 \mathrm{M})=/>0.4126 \mathrm{~s}^{-1}$ 


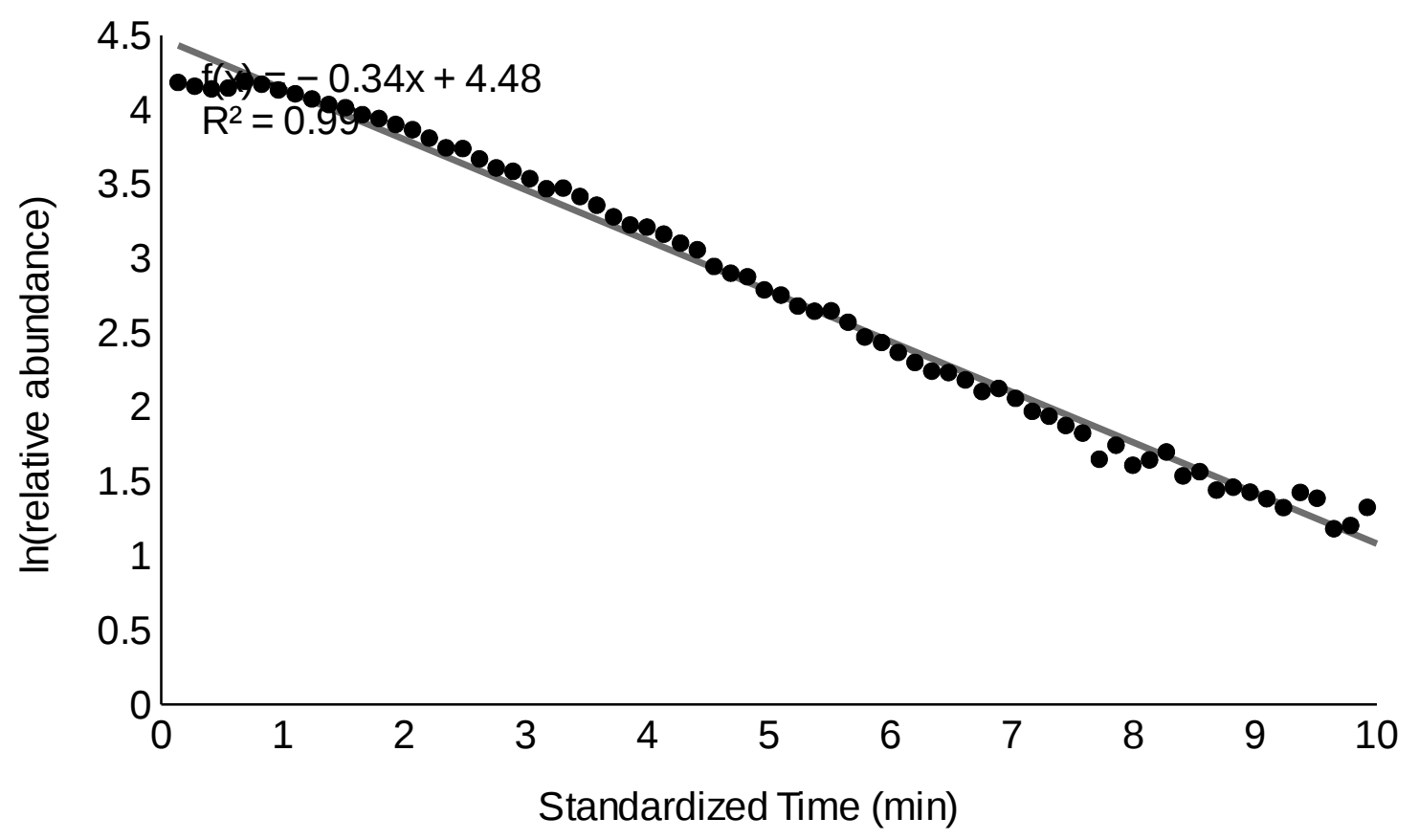

Figure S1: Kinetic plot of In(relative abundance) vs. standardized time, where relative abundance refers to the $[\mathrm{Pd}(\mathrm{sSPhos})(\mathrm{dba})]^{-}$species $(\mathrm{n}=3)$. Time has been standardized such that $\mathrm{t}=0$ represents addition of $\mathrm{Pd}_{2}(\mathrm{dba})_{3}$. Kinetic plots for $[\mathrm{Pd}(\mathrm{L})(\mathrm{Ph})(\mathrm{I})]^{-}$and $[\mathrm{Pd}(\mathrm{L})(\mathrm{Ph})(\mathrm{I})$ $\left.\left(\mathrm{NH}_{2} \mathrm{Ph}\right)\right]^{-}$were constructed in the same fashion.

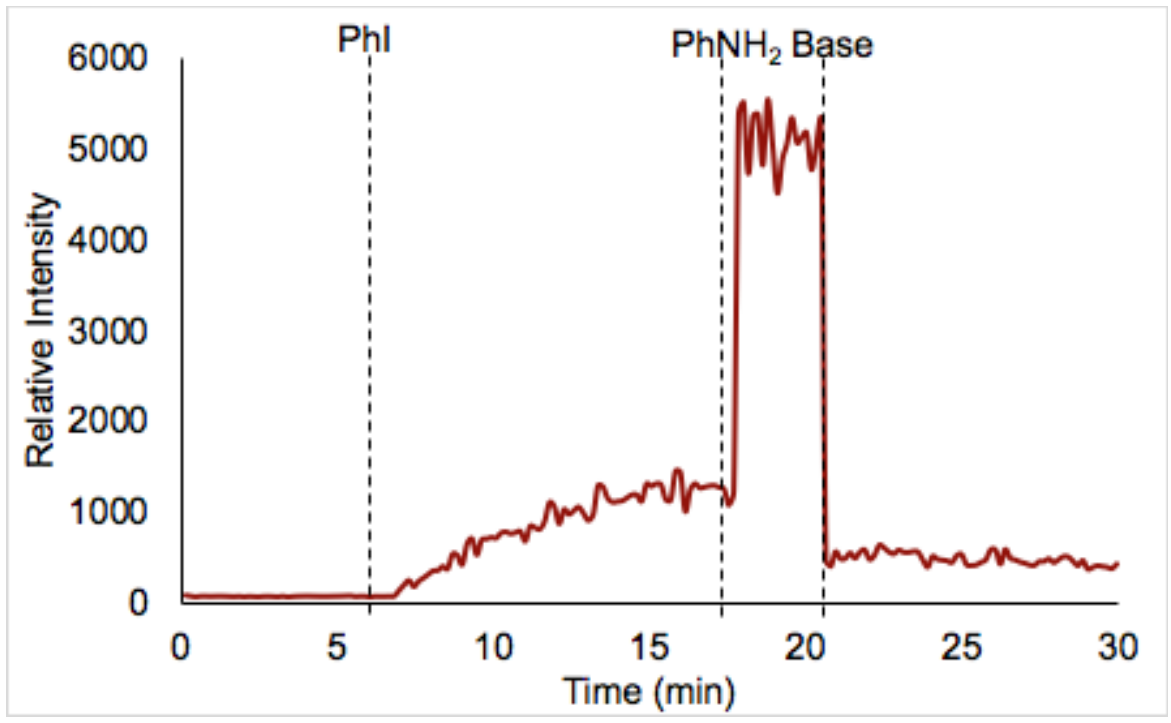


Figure S2: positive ion mode monitoring of the addition of Phl to a solution of $\mathrm{Pd}(\mathrm{SPhos})(\mathrm{dba})$, resulting in the formation of $[\mathrm{Pd}(\mathrm{SPhos})(\mathrm{Ph})]^{+}$.

\section{References}

1 G. T. Thomas, L. MacGillivray, N. L. Dean, R. L. Stoddard, L. P. E. Yunker and J. S. Mclndoe, Int. J. Mass Spectrom., 2019, 441, 14-18. 
Other files 